\title{
Effect of Hydrogen Content and Bonding Environment on Mechanical Properties of Hydrogenated Silicon Films Deposited by High-Frequency PECVD Process
}

\author{
Jhuma Gope, ${ }^{1,2}$ Sushil Kumar, ${ }^{1}$ A. Parashar, ${ }^{1}$ S. Dayal, ${ }^{1}$ \\ C. M. S. Rauthan, ${ }^{1}$ and P. C. Srivastava ${ }^{2}$ \\ ${ }^{1}$ Physics of Energy Harvesting Division, National Physical Laboratory, CSIR, Dr. K.S. Krishnan Road, New Delhi 110012, India \\ ${ }^{2}$ Department of Physics, Banaras Hindu University, Varanasi 221005, India \\ Correspondence should be addressed to Sushil Kumar, skumar@nplindia.org
}

Received 16 April 2012; Accepted 29 May 2012

Academic Editors: T. Benameur, M. R. Ferreira, and S.-H. Kim

Copyright ( $) 2012$ Jhuma Gope et al. This is an open access article distributed under the Creative Commons Attribution License, which permits unrestricted use, distribution, and reproduction in any medium, provided the original work is properly cited.

The mechanical properties of hydrogenated silicon thin films deposited using high-frequency PECVD process were studied, which certainly have importance for optoelectronic devices particularly for getting stability and long operating lifetime in harsh conditions. Nanoindentation technique was used to measure the load versus displacement curves, hardness $(H)$, elastic modulus $(E)$, plastic resistance parameter $(H / E)$, elastic recovery $(E R)$, and plastic deformation energy $\left(U_{r}\right)$, while laser scanning stress measurement setup was used to measure the intrinsic stress of these films. The concentration of bonded hydrogen in these films was found in the range of 3.6 to 6.5 at. \% which was estimated using integrated intensity of IR absorption peak near $640 \mathrm{~cm}^{-1}$. Dependence of mechanical properties of these films on hydrogen content and bonding environment has been investigated. The film containing minimum hydrogen content $(3.6 \%)$ shows the maximum elastic recovery $(52.76 \%)$ and minimum plastic deformation energy $\left(3.95 \times 10^{-10} \mathrm{~J}\right)$. Surface roughness measured by AFM was found to decrease with the increase in hydrogen content in the film. The dependency of stress on the plasma frequency and applied power has also been discussed.

\section{Introduction}

The mechanical properties of amorphous and nano/microcrystalline silicon (a-Si:H and $\mathrm{nc} / \mu \mathrm{c}-\mathrm{Si}: \mathrm{H})$ thin films may play a significant role in the application of silicon-based devices such as solar cells, TFT, detectors, and particularly on flexible substrates because it may affect the stability and operating lifetime of the devices. Besides these, hydrogenated silicon films have also been widely used in MEMS and therefore, it is significant to study the nanomechanical properties of these films [1]. Nanoindentation technique is commonly used to measure the micromechanical properties such as hardness, elastic modulus and creep of thin films [25]. Measurement of intrinsic stress of films is also important as excessive tensile stress may cause cracking, while excessive compressive stress may cause peeling of the deposited thin films [6] which limits their applications for various devices. The formation of intrinsic stress in these films mainly depends on the deposition process and parameters being used. The atomic concentration of hydrogen in the nc/ $\mu \mathrm{c}-\mathrm{Si}: \mathrm{H}$ structure affects the density of films which could be important to correlate with the hardness and elastic modulus. Excess hydrogen incorporation in these films as $\mathrm{Si}-\mathrm{H}$ bond hampers $\mathrm{Si}-\mathrm{Si}$ bond from compact network structure which may be required for formation of crystalline silicon thin film. However, hydrogen has its own importance in hydrogenated amorphous silicon (a$\mathrm{Si}: \mathrm{H})$ as it passivates the dangling bonds and improves the optoelectronic properties. The density of hydrogen in microcrystalline silicon $(\mu \mathrm{c}-\mathrm{Si}: \mathrm{H})$ films is also important as it passivates grain boundaries [7].

Usually, $13.56 \mathrm{MHz}$ frequency is used as the excitation frequency in plasma-enhanced chemical vapor deposition (PECVD) system for the deposition of these films. High rate deposition and photodegradation are major problems of these films [8-10]. High rate deposition of these films 
can also be achieved at high power density $\left(>100 \mathrm{~mW} / \mathrm{cm}^{2}\right)$ and/or high deposition pressure (>1 Torr) using $13.56 \mathrm{MHz}$ frequency PECVD process. However, these approaches deteriorate the film properties as the internal stress becomes high at high deposition rate, the reason being high power density increases ion energy bombardment of growing film surface. On the other hand, deposition at high pressure zone, powder formation may take place which may incorporate in the deposited films. This may cause poor mechanical properties of these films. Dilution of $\mathrm{SiH}_{4}$ with $\mathrm{Ar} / \mathrm{H}_{2} / \mathrm{He}$ may reduce the chance of powder formation even if deposition of nc/ $\mu \mathrm{c}-\mathrm{Si}: \mathrm{H}$ films takes place in the high pressure zone [11].

Alternatively, high quality of a-Si:H and nc/ $\mu \mathrm{c}-\mathrm{Si}: \mathrm{H}$ films at high deposition rate can be achieved using very high frequency (VHF) PECVD process due to lower energy ion bombardment on the growing surface. Microwave (MW) PECVD process can also be used to deposit these films at high growth rate. The mechanical properties of a-Si: $\mathrm{H}$ and nc/ $\mu \mathrm{c}-\mathrm{Si}: \mathrm{H}$ films have not been studied much so far. It would be interesting to study mechanical properties of $\mathrm{nc} / \mu \mathrm{c}$ $\mathrm{Si}: \mathrm{H}$ films having reasonably good electronic properties and deposited using high frequency PECVD process. In the present work, nc-Si : $\mathrm{H}$ thin films were deposited using VHF $(60 \mathrm{MHz})$ as well as VHF coupled with MW $(2.45 \mathrm{GHz})$ power at two power levels in a PECVD system. These films are called nc-Si: $\mathrm{H}$ because they contain small grains of nanosize in amorphous matrix and very low hydrogen (usually high in a-Si: $\mathrm{H}$ ). The influence of hydrogen content and bonding environment on the nanomechanical properties and nature of stress of these films are also discussed in the present investigation.

\section{Experiment Details}

nc-Si:H thin films were deposited in a dual frequency (VHF +/MW) PECVD system having an electrode of area $\sim 140 \mathrm{~cm}^{2}$. These films were grown at various VHF $(60 \mathrm{MHz})$ power as well as VHF $(60 \mathrm{MHz})$ coupled with MW $(2.45 \mathrm{GHz}$ ) (as shown in Table 1), using gaseous mixture of silane $\left(\mathrm{SiH}_{4}\right)$ and Ar, while other parameters such as silane flow (10 sccm), gas pressure ( 0.32 Torr $)$, and substrate temperature $\left(250^{\circ} \mathrm{C}\right)$ remained constant. These films were grown on Si substrates and characterized by X-ray diffraction (XRD), Raman scattering, and atomic force microscopy (AFM) and their nanostructure was observed. All these films contain medium fraction of crystallinity having crystallites size in the range of few nm (estimated using Raman measurement). The thicknesses of all these films were in the range between $700 \mathrm{~nm}$ and $1100 \mathrm{~nm}$ measured using Talystep, M/S Rank Tailor Hobson, UK equipment. The mechanical properties (hardness and elastic modulus) of these films were measured using nanoindenter (IBIS nanoindentation system) having a Berkovich diamond tip with tip radius of $200 \mathrm{~nm}$. Multiple indentations were carried out at $5 \mathrm{mN}$ load for each sample and the values that represent average of the measured data were considered. Intrinsic stress was measured using laser scanning stress measurement setup
TABLE 1: Deposition parameters, film thickness, and bonded hydrogen content $\left(C_{\mathrm{H}}\right)$ of nc-Si : $\mathrm{H}$ films.

\begin{tabular}{lcccc}
\hline Sample & $\begin{array}{c}\text { VHF power } \\
(\mathrm{W})\end{array}$ & $\begin{array}{c}\text { MW power } \\
(\mathrm{W})\end{array}$ & $\begin{array}{c}\text { Thickness } \\
(\mathrm{nm})\end{array}$ & $C_{\mathrm{H}}$ (at. \%) \\
\hline A & 20 & $\mathrm{x}$ & $1100 \pm 20$ & 3.9 \\
B & 40 & $\mathrm{x}$ & $700 \pm 15$ & 6.5 \\
C & 5 & 25 & $800 \pm 17$ & 3.6 \\
D & 10 & 25 & $720 \pm 8$ & 5.2 \\
\hline
\end{tabular}

(M/S FSM 500 TC). Infrared (IR) transmission measurements were performed with an FTIR spectrometer (JASCO $6100)$ to evaluate hydrogen content $\left(C_{\mathrm{H}}\right)$ of nc-Si: H films. Surface roughness was measured by AFM (model: NT-MDT Solver Scanning Probe Microscope) within a surface area of $4.5 \mu \mathrm{m} \times 4.5 \mu \mathrm{m}$. Raman scattering measurement was carried out by Renishaw's inVia Raman microscope using argon laser $(\lambda=514.5 \mathrm{~nm})$ with low beam power in the backscattering mode.

\section{Results and Discussion}

The main aim of this study is to understand the effect of total bonded hydrogen content on the mechanical properties of nc-Si : H films.

3.1. FTIR Analysis. Fourier transform infrared (FTIR) spectroscopy is mostly used to determine hydrogen content in a-Si:H and nc/ $\mu \mathrm{c}-\mathrm{Si}: \mathrm{H}$ thin films. In Figure 1, the FTIR transmission spectra of nc-Si: $\mathrm{H}$ thin films deposited on $\mathrm{Si}$ wafer at different VHF and MW power show the wagging or rocking and stretching modes of the $\mathrm{Si}-\mathrm{H}$ bonding. In $\mu \mathrm{c}-\mathrm{Si}: \mathrm{H}, \mathrm{Si}$ and $\mathrm{H}$ vibrational modes are found near 640 , $840,880,2000$, and $2100 \mathrm{~cm}^{-1}$ in the IR spectra [12]. A broad peak $\sim 637 \mathrm{~cm}^{-1}$ is observed in the IR spectra which may be due to $\mathrm{Si}-\mathrm{H}$ rocking/wagging modes. The band at $800-950 \mathrm{~cm}^{-1}$ is also observed for all the films which may be originated from $\mathrm{SiH}_{2}$ or $\mathrm{SiH}_{3}$ bonding (bending modes). For this band, a relatively low intensity is observed for samples $\mathrm{C}$ and $\mathrm{D}(\mathrm{VHF}+\mathrm{MW}$ power) compared to sample $\mathrm{A}$ and $\mathrm{B}$ (VHF power). The absorption band at $1900-2200 \mathrm{~cm}^{-1}$ may be attributed to $\mathrm{SiH}, \mathrm{SiH}_{2}$, and $\mathrm{SiH}_{3}$ stretching modes. It is known that 2000 and $2100 \mathrm{~cm}^{-1}$ modes in a-Si: $\mathrm{H}$ are assigned to the stretching vibration modes of $\mathrm{SiH}$ and $\mathrm{SiH}_{2}$, respectively, and the $\mathrm{SiH}_{2}$ bonds are mainly located in the internal surface of microvoids [13]. Figure 1 also shows that stretch mode frequencies for all the deposited films are centered around $2000 \mathrm{~cm}^{-1}$ which reveal that the films contain predominantly monohydride $(\mathrm{Si}-\mathrm{H})$ bonding. An appearance of a broad shoulder centred around $\sim 2090 \mathrm{~cm}^{-1}$ has also been observed for all the films. This can be attributed to the formation of nanosize crystallite Si embedded in amorphous matrix. Han et al. [14] referred the absorption band at $2090 \mathrm{~cm}^{-1}$ to the clustered $\mathrm{Si}-\mathrm{H}$ at grain boundaries.

The bonded hydrogen content $C_{\mathrm{H}}$ (in at. \%) has been calculated from the integrated intensity of the $\mathrm{Si}-\mathrm{H}$ 


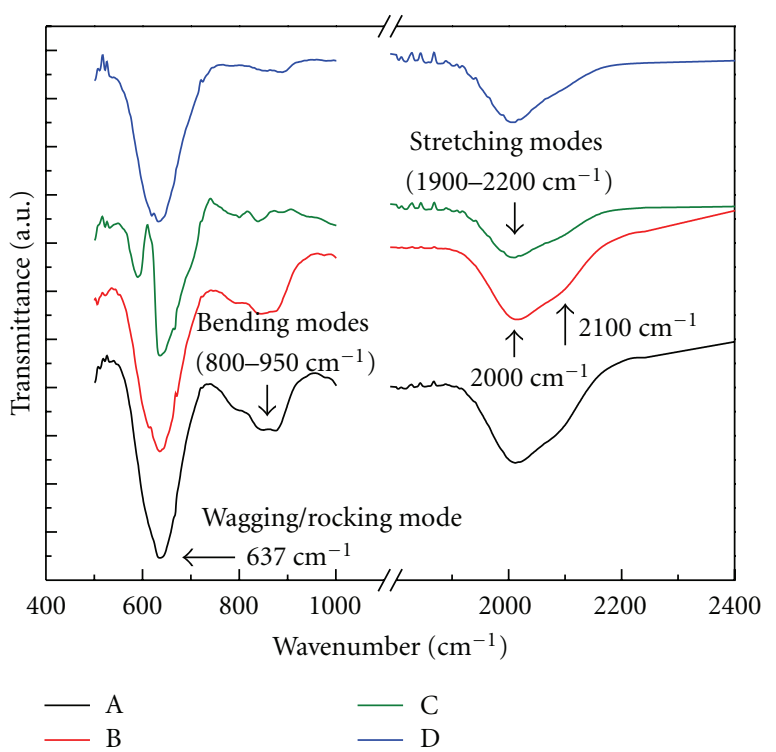

FIGURE 1: FTIR transmittance spectra of nc-Si : H films deposited at different VHF and VHF + MW power.

wagging/rocking modes centered around $640 \mathrm{~cm}^{-1}$ using the following formula:

$$
C_{H}=\left[\frac{\left(A_{\omega} \int \alpha(\omega) d \omega / \omega\right)}{N_{S i}}\right] \times 100 \%
$$

where $\alpha(\omega)$ is the absorption coefficient, $\omega$ is the wave number in $\mathrm{cm}^{-1}, A_{\omega}=1.6 \times 10^{19} \mathrm{~cm}^{-2}$ (oscillator strength), and $N_{S i}=5 \times 10^{22} \mathrm{~cm}^{-3}$ (atomic density of crystalline silicon) [15].

The calculated bonded hydrogen contents of all these films are shown in Table 1. The hydrogen content was found in the range of 3.6 to $6.5 \%$ which is very low for all the deposited films. These films were grown without any additional hydrogen dilution; however, argon (Ar) dilution to $\mathrm{SiH}_{4}$ was used. The lower hydrogen content may be due to use of higher plasma frequency and Ar dilution. The excited Ar ion species may transfer their energy to the growing film surface and break the weak Si-Si bonds and reconstruct more ordered network. Additionally, high frequency causes higher ionization and efficient dissociation and also lowers the ion bombardment energy due to lowering of self-bias [16]. In addition, increase of applied VHF power also enhances the dissociation and ionization of precursor gases; it may also increase the ion bombardment energy similar to RF power. However, ion energy may not increase much with the increase of power as the self-bias does not increase much at higher frequency. However, it is important to have appropriate/optimum ion energy during the growth of nc/ $\mu \mathrm{c}-\mathrm{Si}: \mathrm{H}$ films for the improved mechanical property. Sample B contains more bonded hydrogen than sample A which may be due to increase of VHF power. At high power, the amount of atomic hydrogen is greater in plasma than low power which may affect the growth mechanism of nc/ $\mu \mathrm{c}-$ $\mathrm{Si}: \mathrm{H}$ film by de-attachment of hydrogen with $\mathrm{Si}$, etching of weak bonds, and more random nucleation.
3.2. Nano-Indentation Test. The hardness and elastic modulus of $\mathrm{nc}-\mathrm{Si}: \mathrm{H}$ films were measured by using IBIS nanoindenter which is a load-controlled instrument. The diamond Berkovich indenter was forced into the thin films under constant load condition. Hardness and elastic modulus were determined from the experimental readings of indenter load and depth of penetration. The depth of penetration together with the known geometry of the indenter gives the measure of contact area at maximum load, from which the mean contact pressure and thus hardness were estimated. The area of contact for a perfect Berkovich tip is given as follows:

$$
\begin{gathered}
A=3 \sqrt{3} h_{p}^{2} \tan ^{2} \psi, \\
A \approx 24.5 h_{p}^{2},
\end{gathered}
$$

where $h_{p}$ is the depth of penetration and $\psi=65.3^{0}$ for Berkovich indenter.

The hardness is calculated using the following expression:

$$
H=\frac{P_{\max }}{24.5 h_{p}^{2}},
$$

where $P_{\max }$ is the maximum load.

The elastic modulus is determined from the slope of the unloading curve at maximum load. It is calculated using the following equation:

$$
E=\frac{1}{2} \frac{\sqrt{\pi}}{\sqrt{A}} \frac{d P}{d h},
$$

where $d P / d h$ is stiffness, that is, derivative of a power law fit to the unloading curve and evaluated at the maximum load.

Figure 2 shows the load-displacement curves for the nc$\mathrm{Si}: \mathrm{H}$ films having different hydrogen content. The smooth curves on loading and unloading represent that there is no film fracture and delamination from substrates during nanoindentation. From these curves, the hardness and elastic modulus of the films deposited under different VHF and MW power are determined using (3) and (4), respectively. The maximum indentation depth for the films is $0.137 \mu \mathrm{m}$ which is less than $20 \%$ of the total film thickness. Hence, total deformation is confined within the film and there is no substrate effect. However, if the load is increased beyond a critical limit then the depth of deform region will go into the substrate and give the hardness of film/substrate system. The hardness and elastic modulus of the films as a function of bonded hydrogen content is shown in Figure 3. A decrease in nanohardness and elastic modulus of these films was found with the increase in hydrogen content. The decrease in hardness may be attributed to the decrease in film density which may arise from the mismatch of bonding strength and difference of atomic size of Si and $\mathrm{H}$. It is well known that hydrogen is bonded with $\mathrm{Si}$ as $\mathrm{Si}-\mathrm{H}$ which breaks the compact Si-Si bond. A maximum hardness of $\sim 14.5 \mathrm{GPa}$ is observed for sample $\mathrm{C}$ deposited at dual frequency $(5 \mathrm{~W}$ VHF and $25 \mathrm{~W}$ MW-power) which has the lowest hydrogen content $\left(C_{\mathrm{H}}=3.6 \%\right)$. Hydrogen content has similar effect on modulus of films due to the same reason. 


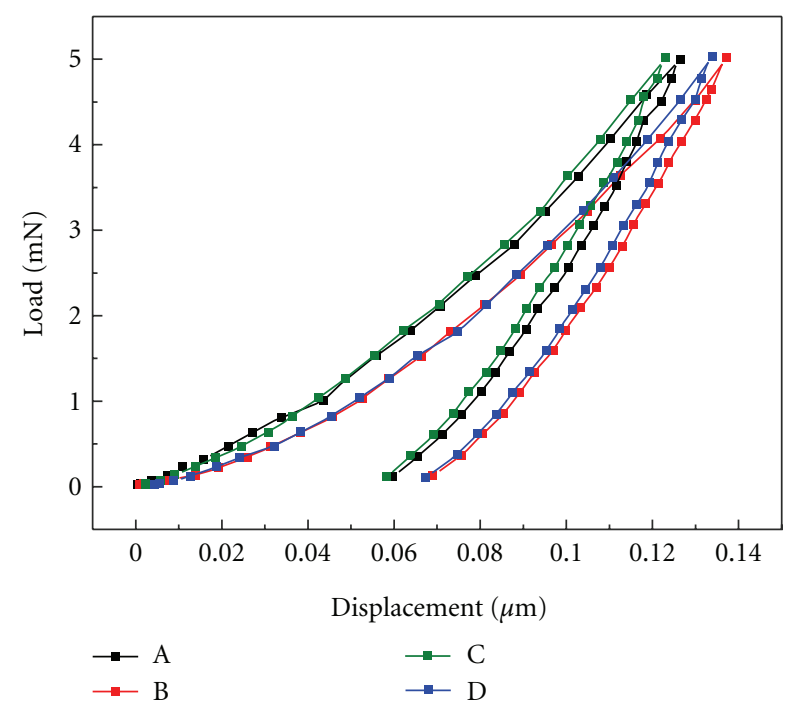

FIGURE 2: Load-displacement curves of nc-Si : H films.

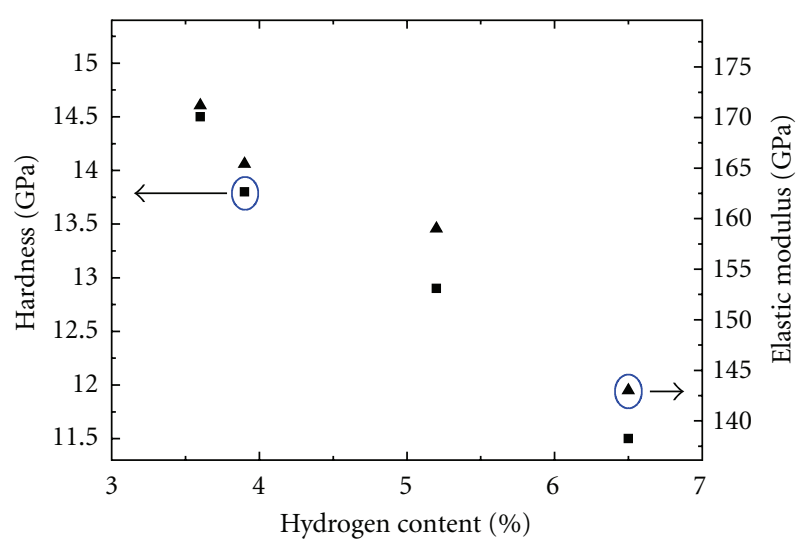

FIGURE 3: The hardness and elastic modulus of nc-Si: $\mathrm{H}$ films as a function of bonded hydrogen content.

From the load-displacement curves, the elastic recovery (ER) has also been calculated. It is defined as follows:

$$
R=\frac{\left(h_{\max }-h_{\mathrm{res}}\right)}{h_{\max }},
$$

where $h_{\max }$ and $h_{\text {res }}$ are the displacement at peak load and residual displacement after load removal, respectively [17]. The recovery is enhanced when the indentation depth is small.

The ratio of hardness and elastic modulus $(H / E)$ is called "plasticity ratio" which is very important for estimating the limit of elastic behavior in a surface contact, essential for wear resistance of a material. Figure 4 shows the elastic recovery ER and H/E ratio $\mathrm{nc}-\mathrm{Si}: \mathrm{H}$ films as a function of hydrogen content. It follows the decreasing trend with hydrogen content-ER and H/E varied from 52.76 to $49.60 \%$ and from 0.084 to 0.080 when hydrogen content increase from 3.6 to $6.5 \%$. Thus, it is revealed that hydrogen incorporation in $\mathrm{nc}-\mathrm{Si}: \mathrm{H}$ films results in the decrease of hardness, elastic recovery, and $H / E$ ratio.

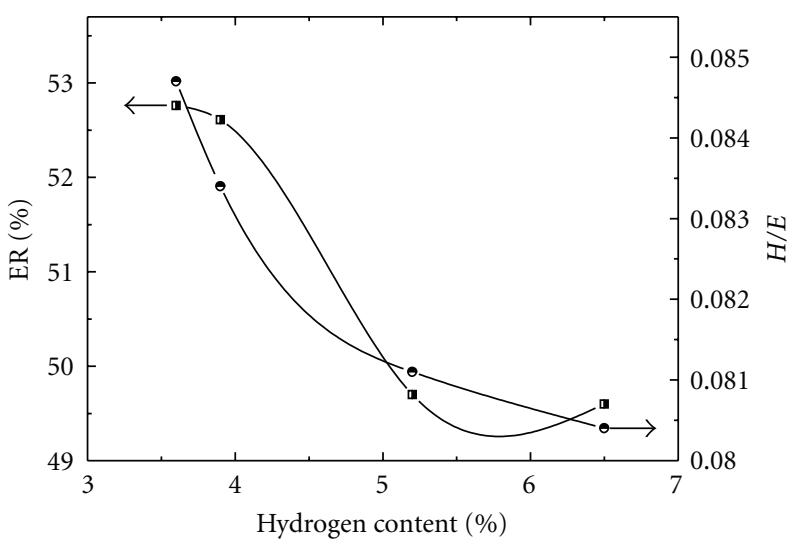

FIgURe 4: Elastic recovery and $H / E$ ratio of nc-Si: $\mathrm{H}$ films as a function of hydrogen content (lines are drawn as a guid to the eyes).

The plastic deformation energy $U_{r}$ of the films was calculated by using the following formula developed by Sakai [18] which is related to the nanohardness of the specimen:

$$
U_{r}=\left[\frac{1}{3} \sqrt{\frac{1}{\omega_{0} \tan ^{2} \Psi}}\right] \frac{1}{\sqrt{H}} P^{3 / 2},
$$

where the geometry constant $\omega_{0}$ is 1.3 for pyramid indenter, $\psi$ is one half of the indenter angle $\left(\psi=65.3^{0}\right.$ for Berkovich indenter), $P$ is the load applied in the indentation test, and $H$ is the hardness value for a given specimen. Figure 5 shows the $U_{r}$ as a function of hydrogen concentration. It increases from $3.95 \times 10^{-10}$ to $4.43 . \times 10^{-10} \mathrm{~J}$ with the increase of hydrogen content from 3.6 to $6.5 \%$ of the films. According to the above equation, plastic deformation energy reduces by an increase in the nanohardness of a specimen. It signifies that the hardness of a specimen rises if the elastic recovery from the indentation test during the unloading process is high because the elastic recovery is inversely proportional to the plastic deformation energy which is also portrayed in Figures 4 and 5. Thus, it is revealed that high hardness is observed in the present case when there is high-elastic recovery and low plastic deformation energy. It is also clear from these studies that the amount of hydrogen in the silicon network is an important factor which decides the hardness value of $\mathrm{nc} / \mu \mathrm{c}-\mathrm{Si}: \mathrm{H}$ films.

3.3. Stress Measurement. The stress of the films was determined by measuring the wafer curvature before and after film deposition. The curvature was measured by laser scanning and stress was calculated from Stoney's equation [19] which is based on the curvature change:

$$
\text { Stress }=\frac{E t_{s}^{2}}{6(1-v) R t_{f}},
$$

where $R=R_{1} R_{2} /\left(R_{1}-R_{2}\right), E$ is the elastic modulus of silicon wafer, $v$ is the Poisson's ratio of silicon wafer, $t_{s}$ is the substrate thickness, $t_{f}$ is the film thickness, $R_{1}$ is the wafer curvature before deposition, and $R_{2}$ is the wafer curvature with deposited film. 


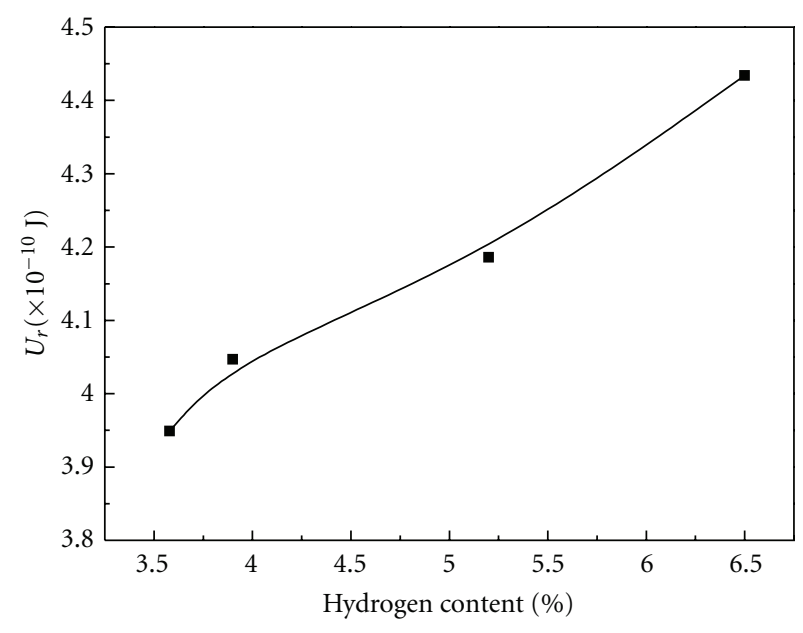

Figure 5: Plastic deformation energy of nc-Si : $\mathrm{H}$ films as a function of hydrogen content (line is drawn as a guid to the eyes).

Figure 6 shows stress of films as a function of hydrogen content. The positive $Y$-axis represents the tensile stress while the negative yaxis represents the compressive stress. Films deposited at $60 \mathrm{MHz}$ frequency (VHF) show compressive stress which increases with the increase of VHF power, whereas films deposited at $60 \mathrm{MHz} / 2.45 \mathrm{GHz}$ dual frequency show tensile stress which also increases with the increase of power. Increase in power causes ions to impinge with high energy on the growing film surface which results in increase in the stress. The various PECVD deposition parameters like temperature, power, pressure, gas flow, and frequency all influence the stress of the deposited films [2022]. In this work, the nature of stress from compressive to tensile may be due to the lower ion bombardment energy at higher frequency. Other researchers have also observed the change in the nature of stress by the variation in plasma frequency, though the frequency range is different from this work [22, 23]. Lopata et al. [24] studied the internal stress in plasma-enhanced chemical vapor deposited $\mathrm{SiN}_{\mathrm{x}}$ films as a function of operating frequency (high, $\gg 1 \mathrm{MHz}$ or low, $\ll 1 \mathrm{MHz}$ ) and obtained moderately high tensile to very high compressive stress values. Usually, the nature and level of stress in the films depends on the energy of ions which is governed by combined effect of various deposition process parameters used in the PECVD system. The optimum ion energy may be different for different materials deposition and thus, transition of tensile to compressive stress or vice versa is observed in a different frequency zone. Here, it is observed that intrinsic stress increases with hydrogen content irrespective of compressive or tensile stress. With the incorporation of $\mathrm{H}$ atom in $\mathrm{Si}-\mathrm{Si}$ network, strain may be produced through decrease in bond length from $2.33 \mathrm{~A}^{0}(\mathrm{Si}-\mathrm{Si})$ to $1.48 \mathrm{~A}^{0}(\mathrm{Si}-\mathrm{H})$. Thus, the ion energy distribution depends on the frequency and power in the PECVD process which affect the stress of the deposited films. It may be concluded that frequency is a dominant factor in deciding the nature of stress rather than applied power. Irrespective of applied power, frequency decides whether the deposited film will be compressive (VHF) or tensile

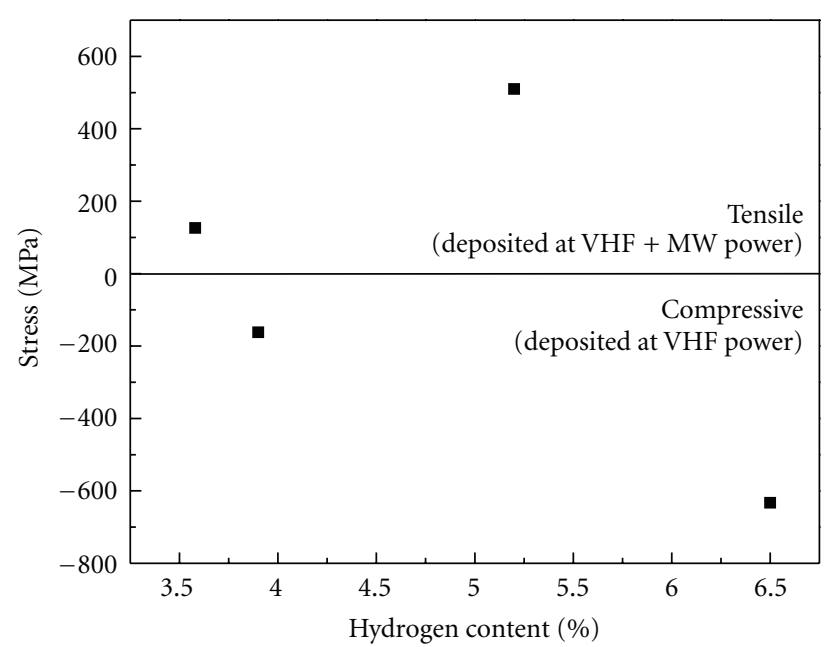

Figure 6: Stress of nc-Si : H films as a function of hydrogen content.

(VHF/MW) in nature. Plasma dynamics and its density and the kinetic energy of the ions change with the change of power and frequency which strongly affect the growing film and could be deciding factors for nature of stress in $\mathrm{nc} / \mu \mathrm{c}-\mathrm{Si}$ : H films.

Usually, residual compressive stresses are expected to increase the resistance to penetration in nanoindentation tests. In contrast, the residual tensile stresses are expected to facilitate the penetration of the indenter. Thus, the influence of nature of stress may affect the estimated value of hardness. This may be due to the difference in contact area of indention on film and actual indenter area. In the present case, there is limitation of measuring the exact contact area of indentation on film due to nonavailability of imaging facility at high resolution. Thus, it is very difficult to draw a conclusion on the effect of nature of stress on the indentation depth and hardness. It is also to be noted that stress values in silicon films are quite lower than the relatively harder films such as diamond-like carbon and nanocomposite of carbon involving metallic clusters. So the effect of nature of stress on indentation depth will be difficult to observe which may also be valid for our films having stress values in the range of $126-633 \mathrm{MPa}$.

In addition, there is decrease of hardness and elastic recovery as a function of increasing hydrogen content, this may be due to change in the bonding environment of hydrogen with silicon and its effect on microscopic state of stress which results into average value of stress either compressive or tensile in nature. This all may be induced by the independent processing conditions of different power levels at two frequencies having different plasma density and electron/ion energy distribution.

3.4. AFM Analysis. Figure 7 shows some typical threedimensional morphologies of the silicon films and variation of the surface root mean square (RMS) roughness $S_{q}$ as a function of $C_{H}$. The rms roughness is given by the 


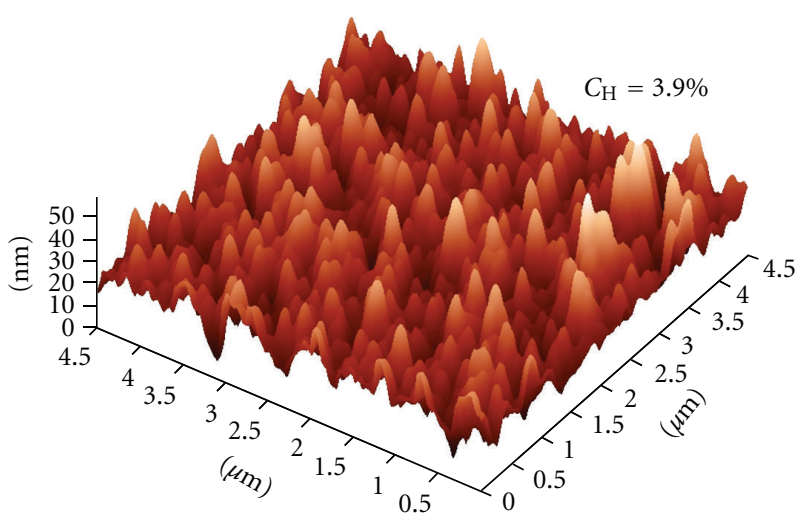

(a)

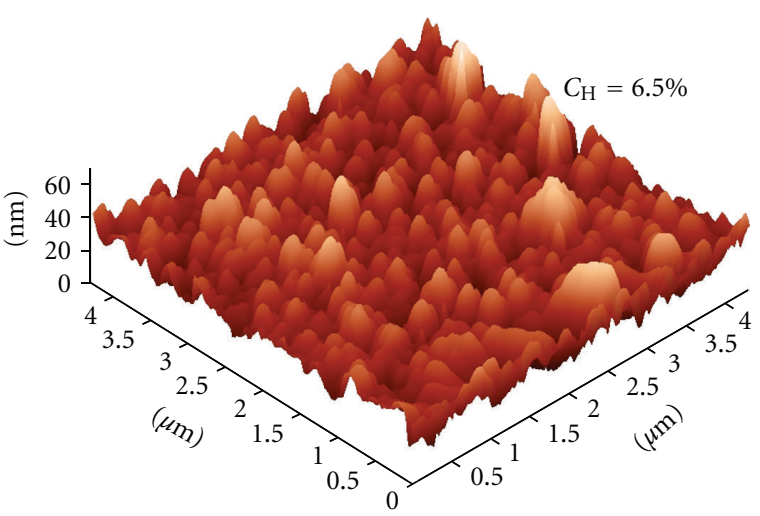

(b)

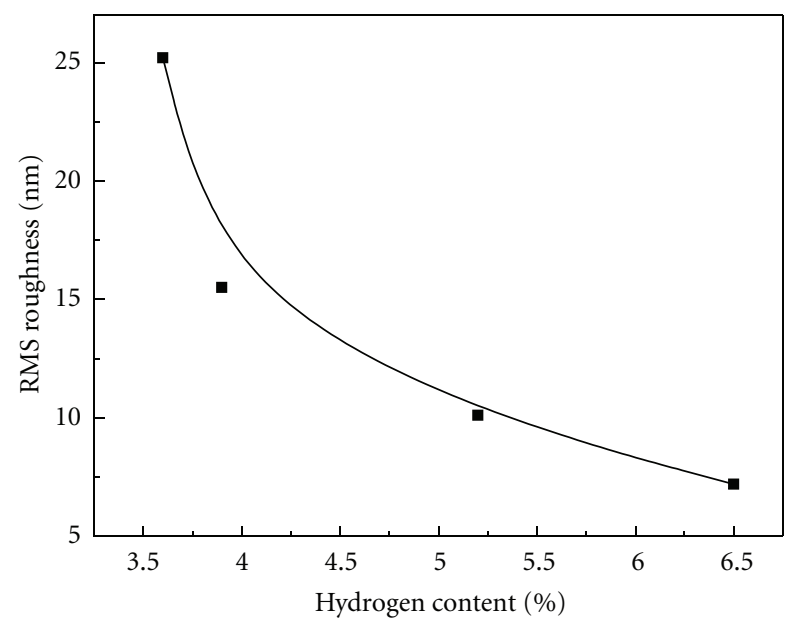

Figure 7: AFM micrographs of (a) sample A $\left(C_{\mathrm{H}}=3.9 \%\right)$ and $(\mathrm{b})$ sample B $\left(C_{\mathrm{H}}=6.5 \%\right)$. Graph shows the variation of surface roughness with $C_{\mathrm{H}} \%$.

standard deviation of the $z$-values for the sample area as follows:

$$
S_{q}=\sqrt{\frac{\sum_{n=1}^{N}\left(z_{n}-z_{\mathrm{avg}}\right)^{2}}{N-1}},
$$

where $z_{\text {avg }}$ is the average of the $z$-values within the given area, $z_{n}$ is the current $z$ value, and $N$ is the number of data points within the given area. RMS roughness is more accurate than the other definitions of roughness such as the mean roughness (the mean value of the surface relative to the center plane) or the peak-to-valley distance (the distance between the highest and the lowest data point of the surface). The AFM micrographs show clear crystalline grains on the surface which also revealed the nanocrystallinity in the films. It shows that roughness decreases from $25.2 \mathrm{~nm}$ to $7.2 \mathrm{~nm}$ as hydrogen content increases from 3.6 to $6.5 \%$. This is quite interesting as surfaces of these films may be passivated by hydrogen as in the present case, with the increase of hydrogen content, the rms roughness values decrease. Surface passivation by hydrogen is well known in case of silicon for photovoltaic devices. Also, it is well recognized for hydrogenated diamond-like carbon (DLC) as lubricant coating for various applications. It is observed that hydrogenated DLC films show less friction than unhydrogenated DLC [25]. In the present study, although it is aimed to emphasize the importance of hydrogen on mechanical properties of silicon film; however, it also affects the surface properties.

3.5. Raman Spectroscopy. Figure 8 shows the Raman spectra of the films containing different hydrogen content. These spectra were deconvoluted into four Gaussian distributions within the scanned range $\left(100 \mathrm{~cm}^{-1}-550 \mathrm{~cm}^{-1}\right)$ at (i) $480 \mathrm{~cm}^{-1}$ representing the transverse optic (TO) peak, (ii) $\sim 146 \mathrm{~cm}^{-1}$ representing the transverse acoustic (TA) peak, (iii) $\sim 330 \mathrm{~cm}^{-1}$ representing the longitudinal acoustic (LA) peak, and (iv) $\sim 440 \mathrm{~cm}^{-1}$ representing longitudinal optic (LO) peak. The TO peak of a-Si:H has occurred around $480 \mathrm{~cm}^{-1}$, whereas the TO peak of crystalline $\mathrm{Si}$ icon (c-Si) is at $520 \mathrm{~cm}^{-1}$. For nanocrystalline materials, the distribution of phonon states changes due to quantum effects and stress, and TO peak is shifted towards lower wave numbers [26]. It is very difficult to analyze the total crystalline volume fraction $\left(X_{c}\right)$ quantitatively, for the films containing very low $X_{c}$ and small crystals dimensions. However, for the $\mathrm{nc}-\mathrm{Si}: \mathrm{H}$, the presence of very small crystals $(2-3 \mathrm{~nm})$ produces a narrow Raman signal around $\sim 490-500 \mathrm{~cm}^{-1}$, 

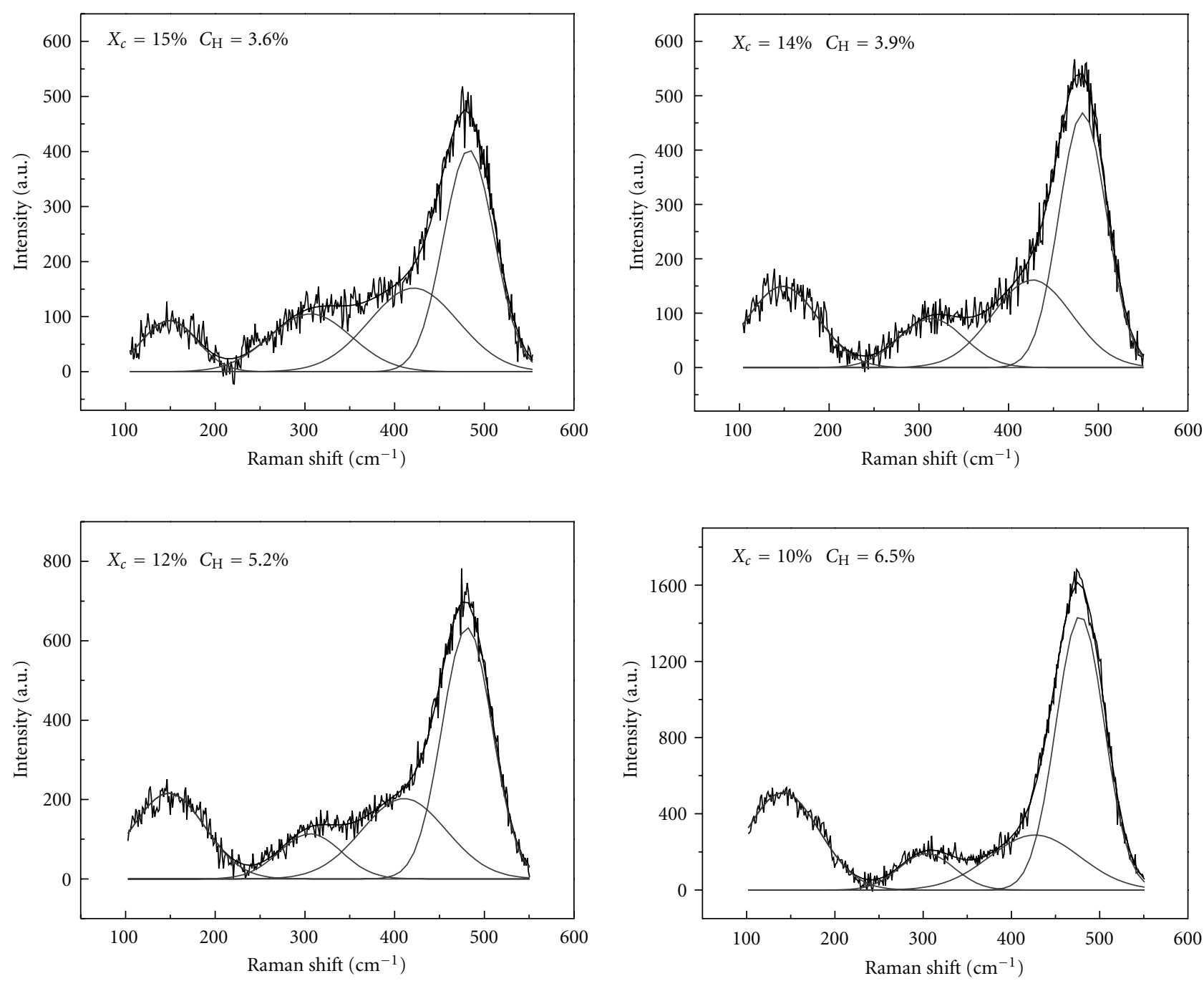

Figure 8: Raman spectra of nc-Si:H films having various crystalline fraction and hydrogen content (deconvoluted into four Gaussian distributions).

which is superimposed on the amorphous TO peak. The TO peak is deconvoluted (using combination of Gaussian and Lorentzian fitting) into two parts, a peak centered around $\sim 468-475 \mathrm{~cm}^{-1}$ from amorphous contribution and another with a peak centered around $\sim 496-500 \mathrm{~cm}^{-1}$ from the contribution of small size crystallites. In the analysis of Raman spectra, the ratio of areas under the TO peaks was considered as a measure of the crystalline to amorphous fraction. The crystalline volume fractions of the nc-Si:H films are depicted in the Figure 8. The ratio between the intensity of TA peak and TO peak is a measure of the topological ordering. Figure 9 shows the variation of $I_{\mathrm{TA}} / I_{\mathrm{TO}}$ with the variation of hydrogen content. From Raman analysis, it was observed that films with lower hydrogen content contain higher crystalline fraction and better $\mathrm{Si}-$ $\mathrm{Si}$ network ordering. The improvement in the topological ordering and increase in crystalline fraction of these films result in enhancement of the hardness and reduction in stress.

\section{Conclusion}

Nanoindentation and stress measurements were performed on nc-Si:H films deposited using VHF and dual frequency $(\mathrm{VHF}+\mathrm{MW})$ PECVD techniques. The hydrogen content of these films was calculated using FTIR absorption peak centered around $640 \mathrm{~cm}^{-1}$. The changes in the mechanical properties of nc-Si:H films with the bonded hydrogen content have been observed. It was found that incorporation of hydrogen in these films decreases hardness, elastic recovery, and wear resistance of the films and increases the plastic deformation energy. Increase in hydrogen content also increases the intrinsic stress of the films. The nature of the stress primarily depends on the growing film condition. Increase of applied power of VHF and MW + VHF process increases stress differently as compressive and tensile stress, respectively. Films having low hydrogen content show better topological ordering of the silicon matrix; however, it increases surface roughness. Excellent mechanical properties of $\mathrm{nc}-\mathrm{Si}: \mathrm{H}$ films observed in the present investigation are 


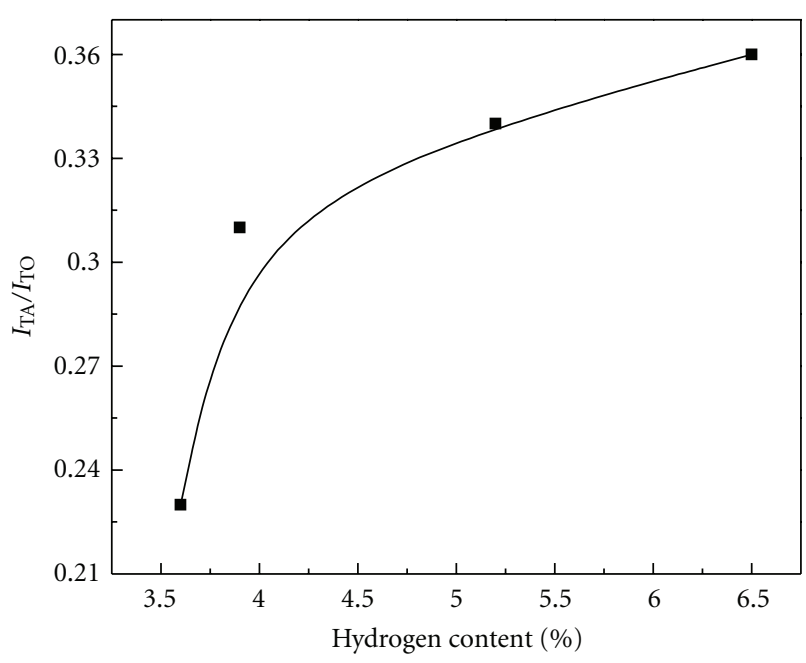

Figure 9: Raman $I_{\mathrm{TA}} / I_{\mathrm{TO}}$ ratio of nc-Si: $\mathrm{H}$ films as a function of hydrogen content (line is drawn as a guid to the eyes).

very important for getting good stability and long operating lifetime of devices especially when made on flexible substrates.

\section{Acknowledgments}

Authors are grateful to the Director, NPL, New Delhi, for his kind support and encouragement. The authors are also thankful to Dr. Ritu Srivastava, NPL, and Mr. Nitin Arya, IIT, Mumbai for providing AFM and FTIR measurements, respectively. The authors also acknowledge CSIR-India and MNRE Govternment of India (sanction no. 31/29/201011/PVSE) for their financial support. One of authors J. Gope also acknowledges CSIR for providing fellowship.

\section{References}

[1] H. Y. Peng, J. L. Wang, L. Wang, and B. Zhou, "The influence of annealing on mechanical properties of hydrogenated nanocrystalline silicon thin films," Journal of Physics, vol. 152, Article ID 012016, 2009.

[2] Y. S. Zou, Y. F. Wu, R. F. Huang, C. Sun, and L. S. Wen, "Mechanical properties and thermal stability of nitrogen incorporated diamond-like carbon films," Vacuum, vol. 83, no. 11, pp. 1406-1410, 2009.

[3] V. Bursikova, P. Sladek, P. Stahel, and J. Bursik, "Mechanical properties of thin silicon films deposited on glass and plastic substrates studied by depth sensing indentation technique," Journal of Non-Crystalline Solids, vol. 352, p. 1242, 2006.

[4] A. Tekaya, S. Labdi, T. Benameur, A. Piatkowska, P. Aubert, and J. Jagielski, "Synthesis and optimization of Ti-TiN multilayered protective nanocoatings on $\mathrm{Zr}$-based bulk metallic glass," Surface and Coatings Technology, vol. 205, no. 11, pp. 3404-3410, 2011.

[5] A. Tekaya, S. Labdi, T. Benameur, and A. Jellad, "Quasistatic cyclic loadings induced inelastic deformation in a $\mathrm{Zr}$ based bulk metallic glass under nanoindentation," Journal of Materials Science, vol. 44, no. 18, pp. 4930-4938, 2009.
[6] I. Kobayashi, T. Ogawa, and S. Hotta, "Plasma-enhanced chemical vapor deposition of silicon nitride," Japanese Journal of Applied Physics, vol. 31, pp. 336-342, 1992.

[7] T. Itoh, K. Yamamoto, H. Harada et al., "Role of hydrogen in hydrogenated microcrystalline silicon," Solar Energy Materials and Solar Cells, vol. 66, no. 1-4, pp. 239-244, 2001.

[8] D. L. Staebler and C. R. Wronski, "Reversible conductivity changes in discharge-produced amorphous Si," Applied Physics Letters, vol. 31, p. 292, 1977.

[9] J. Meier, R. Fluckiger, H. Keppner, and A. Shah, "Complete microcrystalline $\mathrm{p}-\mathrm{i}-\mathrm{n}$ solar cell—crystalline or amorphous cell behavior?” Applied Physics Letters, vol. 65, p. 860, 1994.

[10] M. Kondo and A. Matsuda, "Novel aspects in thin film silicon solar cells-amorphous, microcrystalline and nanocrystalline silicon," Thin Solid Films, vol. 457, no. 1, pp. 97-102, 2004.

[11] S. Kumar, J. Gope, A. Kumar, A. Parashar, C. M. S. Rauthan, and P. N. Dixit, "High pressure growth of nanocrystalline silicon films," Journal of Nanoscience and Nanotechnology, vol. 8, no. 8, pp. 4211-4217, 2008.

[12] T. Itoh, K. Yamamoto, K. Ushikoshi, S. Nonomura, and S. Nitta, "Characterization and role of hydrogen in nc-Si:H," Journal of Non-Crystalline Solids, vol. 266-269, pp. 201-205, 2000.

[13] M. Zhu, Y. Cao, X. Guo, J. Liu, M. He, and K. Sun, "Microstructure of poly-Si thin films prepared at low temperatures," Solar Energy Materials and Solar Cells, vol. 62, p. 109, 2000.

[14] D. Han, K. Wang, J. M. Owens et al., "Hydrogen structures and the optoelectronic properties in transition films from amorphous to microcrystalline silicon prepared by hot-wire chemical vapor deposition," Journal of Applied Physics, vol. 93, no. 7, pp. 3776-3783, 2003.

[15] H. Shanks, C. J. Fang, L. Ley, M. Cardona, F. J. Demond, and S. Kalbitzer, "Infrared spectrum and structure of hydrogenated amorphous silicon," Physica Status Solidi (B), vol. 100, p. 43, 1980.

[16] S. Kumar, P. N. Dixit, D. Sarangi, and R. Bhattacharya, "High rate deposition of diamond like carbon films by very high frequency plasma enhanced chemical vapor deposition at $100 \mathrm{MHz}$," Journal of Applied Physics, vol. 93, p. 6361, 2003.

[17] J. Qi, J. Luo, S. Wen, J. Wang, and W. Li, "Mechanical and tribological properties of non-hydrogenated DLC films synthesized by IBAD," Surface and Coatings Technology, vol. 128-129, p. 324, 2000.

[18] M. Sakai, "Energy principle of the indentation-induced inelastic surface deformation and hardness of brittle materials," Acta Metallurgica et Materialia, vol. 41, pp. 1751-1758, 1993.

[19] G. G. Stoney, "The tension of metallic films deposited by electrolysis," Proceedings of the Royal Society A, vol. 82, no. 553, pp. 172-175, 1909.

[20] J. Dutta, U. Kroll, P. Chabloz et al., "Dependence of intrinsic stress in hydrogenated amorphous silicon on excitation frequency in a plasma-enhanced chemical vapor deposition process," Journal of Applied Physics, vol. 72, no. 7, pp. 32203222, 1992.

[21] P. L. Ong, J. Wei, F. E. H. Tay, and C. Iliescu, "A new fabrication method for low stress PECVD-SiN $\mathrm{x}_{\mathrm{x}}$ layers," Journal of Physics, vol. 34, no. 1, pp. 764-769, 2006.

[22] K. D. Mackenzie, D. J. Johnson, M. W. DeVre, R. J. Westerman, and B. H. Reelfs, "Stress control of Si-based PECVD dielectrics," in Proceedings of the 207th Electrochemical Society Meeting, pp. 148-159, May 2005. 
[23] E. P. van de Ven, I. W. Connick, and A. S. Harrus, "Advantages of dual frequency PECVD for deposition of ILD and passivation films," in Proceedings of the 7th International IEEE VLSI Multilevel Interconnection Conference, pp. 194-201, June 1990.

[24] J. Lopata, W. C. Dautremont-Smith, and J. W. Lee, "Control and variation of stress in pecvd $\mathrm{SiN}_{\mathrm{x}}$ films on InP," Materials Research Society Symposium Proceedings, vol. 130, p. 361, 1989.

[25] J. Fontaine, J. L. Loubet, T. Le Mogne, and A. Grill, "Superlow friction of diamond-like carbon films: a relation to viscoplastic properties," Tribology Letters, vol. 17, no. 4, pp. 709-714, 2004.

[26] J. Zi, H. Buescher, C. Faler, W. Ludwig, K. Zhang, and X. Xie, "Raman shifts in Si nanocrystals," Applied Physics Letters, vol. 69, p. 200, 1996. 

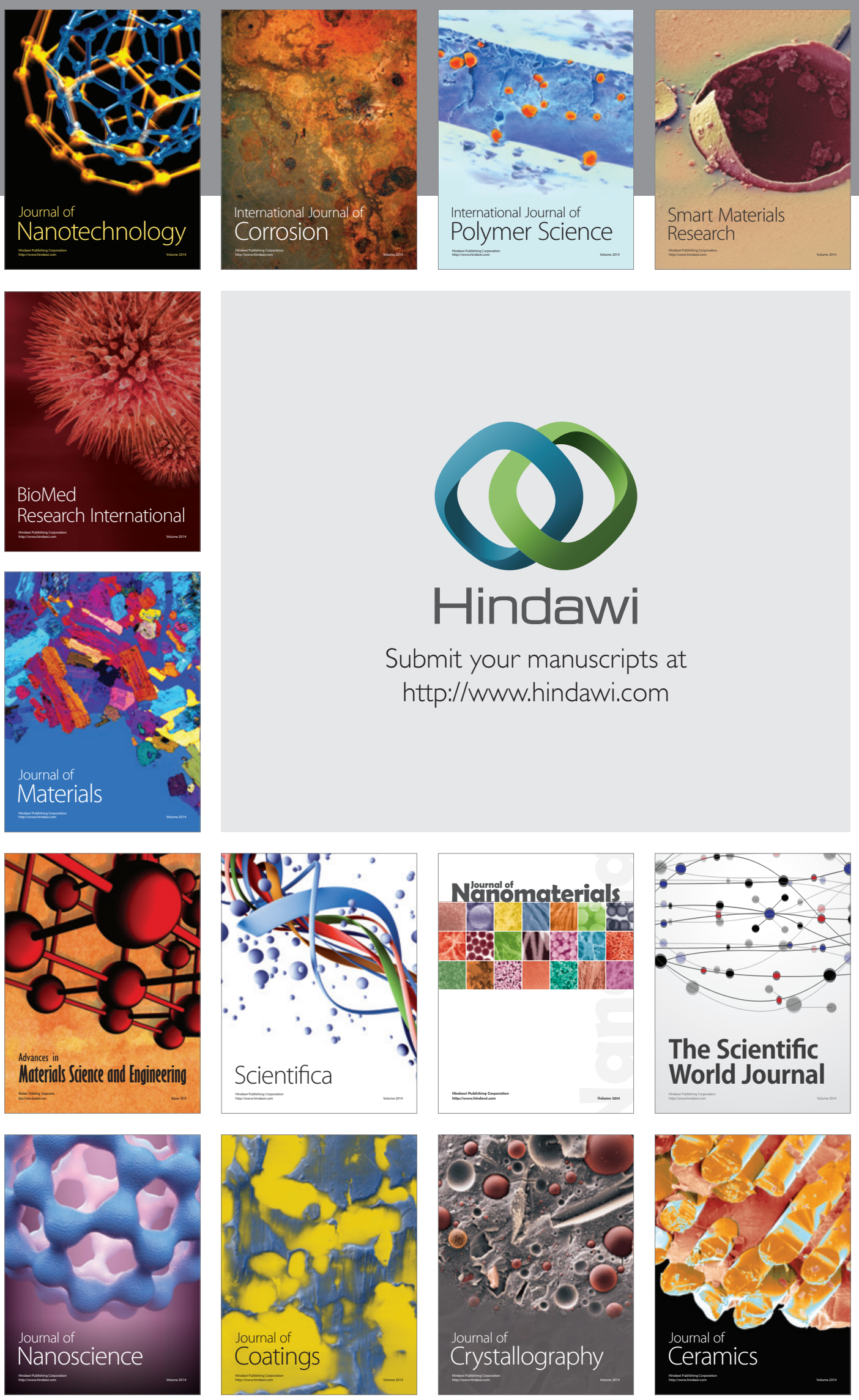

The Scientific World Journal

Submit your manuscripts at

http://www.hindawi.com

\section{World Journal}

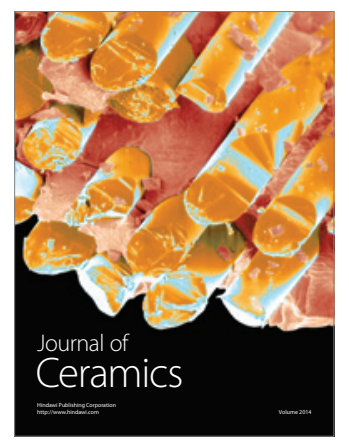

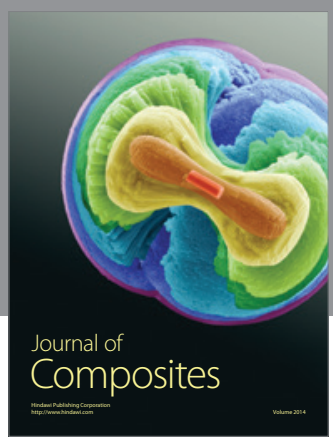
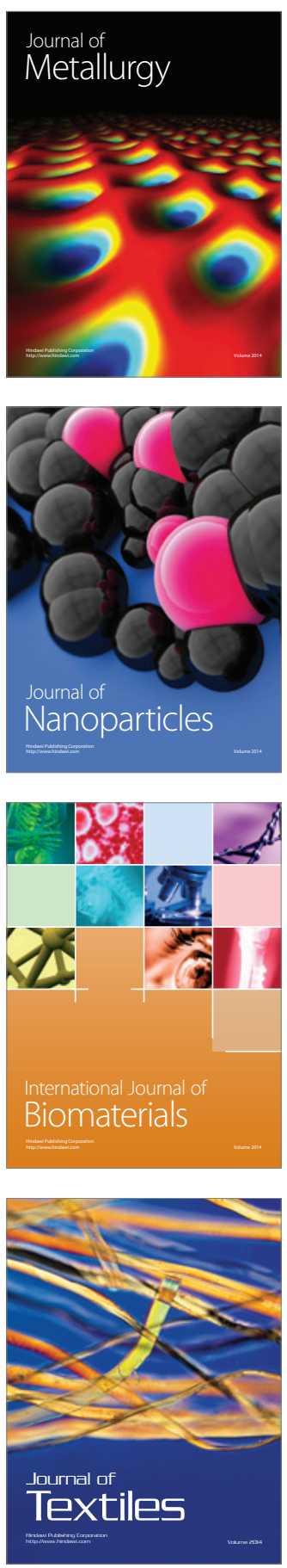